\title{
Quantifying the increase in fishing efficiency due to the use of drifting FADs equipped with echosounders in tropical tuna purse seine fisheries
}

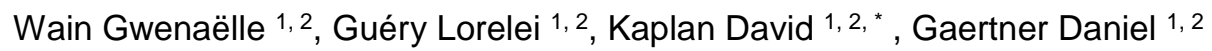

\author{
${ }^{1}$ MARBEC, Univ Montpellier, CNRS, Ifremer, IRD, Sète, France \\ 2 Institut de Recherche pour le Développement (IRD), UMR MARBEC, Av. Jean Monnet, CS 30171 , \\ Sète Cedex 34203, France \\ * Corresponding author : David Kaplan, email address : david.kaplan@ird.fr
}

\begin{abstract}
:
Numerous pelagic species are known to associate with floating objects (FOBs), including tropical tunas. Purse seiners use this behaviour to facilitate the capture of tropical tunas by deploying artificial drifting fish aggregating devices (dFADs). One major recent change has been the integration of echosounders in satellite-tracked GPS buoys attached to FOBs, allowing fishers to remotely estimate fishable biomass. Understanding the effects of this new technology on catch of the three main tuna species (yellowfin tuna, Thunnus albacares; bigeye tuna, Thunnus obesus; and skipjack tuna, Katsuwonus pelamis) is important to accurately correct for this change in catch-per-unit-effort (CPUE) indices used for stock assessments. We analysed catch data from the French purse seine fleet for the period 2010-2017 in the Indian Ocean to assess the impact of this fleet's switch to echosounder buoys around 2012. Results indicate that echosounders do not increase the probability a set will be succesful, but they have a positive effect on catch per set, with catches on average increasing by $\approx 2-2.5$ tonnes per set $(\approx 10 \%)$ when made on the vessel's own dFADs equipped with an echosounder buoy. Increases were due to a decrease in sets below $\approx 25$ tonnes and an increase in those greater than $\approx 25$ tonnes, with a non-linear transition around this threshold. This increase explains the considerable investment of purse seiners in echosounder buoys, but also raises concerns about bias in stock size estimates based on CPUE if we do not correct for this fishing efficiency increase.
\end{abstract}

Keywords : catch per unit effort, hyperstability, Indian Ocean, standardization 


\section{${ }_{55} 1$ Introduction}

Technological change has been a driving force behind increases in fishing efficiency worldwide for many decades now. For example, several studies have highlighted the substantial impact of new technology on catch rates of demersal fishes (Marchal et al. 2007), of tunas and billfishes caught by pelagic longlines (Ward 2008) and on the impact of global positioning systems (GPS) and plotter systems on the relative fishing power in a prawn fishery (Robins et al. 1998). If the increase due to this new technology is not properly quantified and integrated into stock assessments, they will bias stock size estimates based on raw catch per unit effort (CPUE) derived from captain's logbooks or observer data towards larger stock size, potentially leading to cryptic overfishing and hyperstability (Fonteneau et al. 1999, Maunder \& Punt 2004). The process of correcting for this bias, known as CPUE standardization, is crucial to avoiding stock assessment errors that can lead to incorrect management decisions. However, for CPUE standardization to correctly account for bias, it is essential that data exist on when and where a given technology is being used and that the effect size be quantified via statistical analyses (Bishop 2006). Unfortunately, this information is often unavailable. For example, in the case of the European tropical tuna purse seine fishery that is the subject of this paper, it has been shown that new technologies have been introduced continuously over time, but the lack

${ }^{*}$ Corresponding author; Email: gwenaelle.wain@gmail.com, david.kaplan@ird.fr; Telephone: +334 $995732 \quad 25$ 
of a coordinated introduction of specific technologies across vessels and fleets and the absence of fine scale data (i.e., the date of the first use at the level of individual vessels and fishing trips) on these technologies has often made it difficult or impossible to fully account for their impact on catch rates (Gaertner \& Pallarés 2002). These issues represent a significant barrier to the use of purse seine CPUE data for stock assessments. One aspect of tropical tuna purse seine fisheries that has seen significant technological change over recent decades is fishing on fish schools associated with floating objects (FOBs) (for a discussion of FOB terminology, see (Gaertner et al. 2016, ICCAT 2016)). Tropical tuna purse seine fishing is dominated by two fishing modes : fishing on free schools (FSC) that are not associated with any object, and fishing on FOBs. Though purse seiners have always fished on randomly encountered natural flotsam, since the early 1990s increasingly sophisticated technology has been used to deploy and track man-made FOBs, here referred to as drifting fish aggregating devices (dFADs) (Ariz et al. 1999, Hallier \& Parajua 1999). Today, the vast majority of FOB catch occurs on dFADs, and over $50 \%$ of the tropical tuna caught in purse-seine fisheries are caught under FOBs (Fonteneau et al. 2013). This dominance is in no small part due to the use of tracking technology to remotely observe FOB movements in relation to oceanographic processes and historical catch patterns. Initially consisting of radio beacons attached to FOBs (both natural objects and dFADs), these have been replaced since the early 2000s with satellite-transmitting GPS buoys allowing fishers to determine a FOBs location from virtually anywhere on the ocean (Torres-Irineo et al. 2014). The use of this tracking technology has broken the link between searching time and effective fishing effort for FOB sets as vessels can move directly towards a buoy, avoiding or significantly reducing searching time (Fonteneau et al. 1999). Most recently, echosounders have been integrated into GPS tracking buoys, remotely providing fishers information on the presence of tunas under the FOB, sometimes with a rough estimate of the fishable biomass (Baidai et al. 2020). This most recent innovation represents a major change in the way purse seiners fish that must be accounted for to properly evaluate trends in nominal CPUE values. Assessing these impacts is particularly important given that FOB fishing has been 
associated with increased juvenile catch, bycatch, ghost fishing and potential disturbance to pelagic ecosystems (Hallier \& Gaertner 2008, Filmalter et al. 2013, Kaplan et al. 2014).

Here, we use a large dataset of fishing activity, catch rates and GPS-buoy trajectories to examine the impact of echosounder buoys on catch rates for French tropical tuna purse seine vessels in the Indian Ocean from 2010 to 2017. French purse seiners switched to using almost exclusively echosounder equipped buoys after late-2011/early-2012, and in recent years $55-90 \%$ of fishing sets by this fleet are on FOBs. As this dataset spans the period before, during and after this transition to echosounder buoys, we are able to estimate the impact of echosounders on catch rates. The key pieces of information essential to this estimation that were previously missing from catch-effort data are the ownership (i.e., whether or not the vessel has access to buoy information) and capabilities of the GPS-buoy attached to the FOB associated with a fishing set. By combining data on FOB fishing sets with information on GPS-buoy models, trajectories, position reporting rates and owner information, we are able to identify whether or not each set is on a FOB equipped with an echosounder buoy owned by the fishing vessel. Using this information, we can separate out catch on (i) FOBs not tracked by the fishing vessel from FOBs tracked by the fishing vessel (ii) with and (iii) without an echosounder, allowing us to assess differences in catch between the three.

\section{Materials \& Methods}

\subsection{Data}

Logbook catch and effort data and FOB trajectory data for French purse seine vessels operating in the Indian Ocean from 2010 to 2017 were used in this study. Data were provided by the fishing fleet to the IRD-Observatory of Exploited Tropical Pelagic Ecosystems (Ob7) based in the MARBEC research laboratory via an agreement with ORTHONGEL, the French frozen tuna producers' organization. Logbook data included the name and unique identifier of the fishing vessel, the date and geographical coordinates of each fish- 
ing set, the type of fish school (FOB or FSC), and the catch in tonnes for each of the three main tropical tuna species (skipjack, yellowfin and bigeye). Null sets, i.e., sets for which the fishing vessel was unable to capture the associated fish school resulting in catch $<1$ tonne, were included in the dataset. Catch species composition data reported in logbooks were corrected based on port sampling using the T3 software (Pianet et al. 2000). Fishing sets were assigned to one of four monsoon-based seasons (Escalle et al. 2017): 1=December-March, 2=April-May, 3=June-September and 4=October-November.

FOB trajectory data consisted of the make and model of the tracking buoy, the unique numerical identifier of the buoy, and the date, time and geographical coordinates of each buoy position. Tracking buoys typically emitted 1-2 positions per day, though the transmission rate was often increased to as much as 1 position every 15 minutes when vessels were actively tracking an individual FOB with the intention of carrying out a fishing set. Tracking buoys were assumed to be attached to a FOB, with the vast majority of these being dFADs in recent years (>90\% based on observer data), though the data themselves do not indicate what the buoy is attached to. Buoys from the manufacturer Marine Instruments, which dominate French deployments from 2012 onward, also included echosounder data, if the buoy had one, and a list of vessel or company names with access to the buoy trajectory and echosounder data. Buoy positions were classified into onboard and in the water positions using a random forest algorithm based primarily on buoy speed, water temperature and timestep between successive positions (Maufroy et al. 2015, Imzilen et al. 2020).

French logbook and FOB trajectory data were considered to be exhaustive over the period of this study.

\subsection{Determination of buoy ownership}

For this study, we needed to determine for each FOB fishing set if the fishing vessel had access to the buoy trajectory and, if available, echosounder data. For Fishing sets on FOBs equipped with more recent Marine Instruments buoys (in wide use by the French fleet after $\approx 2012$ ), the primary method of making this determination was based on the 
vessel names found in both the logbook and the buoy trajectory data. Specifically, for all buoys located less than $11 \mathrm{~km}$ from the fishing set location within \pm 18 hours of 00:00 UTC the day of the fishing set, we considered that the fishing vessel had access to the buoy position information if (1) the name of the vessel carrying out the set matched one of the vessel names associated with the trajectory data, (2) at least 2 days of buoy trajectory data were available during the 5 days prior to the fishing set, (3) the buoy trajectory for the 5 days preceding the fishing set was classified as being in the water $>=90 \%$ of the time, and (4) the minimum time between successive buoy positions was $<=1$ hour at some point over the 5 days preceding the set. The temporal window of \pm 18 hours was needed as logbook data do not include the time of day of the fishing set. Specifically, \pm 18 hours was used to assure that at least one buoy position was included in the time period and based on the fact that the majority of fishing sets on FOBs occur in the morning between 1 hour before local sunrise and 10 hours after local sunrise (based on anecdotal evidence and post hoc comparisons between logbook set locations and vessel trajectory data), which translates to no later than 18:00 UTC for the Indian Ocean. The spatial filter of $11 \mathrm{~km}$ was based on typical maximum distances buoys travel over a single day (Snouck-Hurgronje et al. 2018). The condition of 2 days of trajectory data was imposed to eliminate buoys deployed shortly before or after the fishing set was carried out. The final two conditions were imposed to assure that the buoy was actually in the water preceding the fishing set and not simply on board, and that the vessel was actively trying to track the buoy by remotely lowering the time between successive transmissions of its position, respectively.

As Marine Instruments buoys were only in wide use by the French fleet after $\approx 2012$, and from 2010-2013 Marine Instruments buoy trajectory data were often associated with company names instead of the names of individual fishing vessels, a second vessel-buoy association method based on separation distance was also used. If there was a FOB buoy trajectory that met all of the aforementioned conditions except the condition on matching vessel names, but that buoy was within $4 \mathrm{~km}$ of the set location, then it was also considered that the fishing vessel had access to the buoy data. The distance of $4 \mathrm{~km}$ was 
based on the observation that minimum separation distance for owned FOB sets meeting the prior association conditions based on vessel names was $<4 \mathrm{~km}$ in the vast majority of cases $(73 \%)$, whereas minimum separations for other types of sets (e.g., free school sets, foreign dFAD sets), for which there should be no valid buoy trajectory association, were generally much greater than this distance.

Based on these determinations and whether or not the associated buoy model possesses an echosounder, each FOB fishing set was placed in one of three set categories:

- Foreign (F), meaning that the fishing vessel had no access to buoy tracking information for the FOB upon which they fished

- Owned-echosounder (O-E), meaning the fishing vessel had access to the buoy tracking data, but the buoy model was not echosounder equipped

- Owned + echosounder $(\mathrm{O}+\mathrm{E})$, meaning the fishing vessel had access to tracking and echosounder data

Note that the term foreign is used in the sense of not pertaining to the fishing vessel as opposed to not being from a specific flag (e.g., France), and the term owned may refer to buoys shared by multiple vessels, one of which is the vessel carrying out the set.

To assess the accuracy of our FOB ownership assignment methodology, we carried out the following tests: (1) the fraction of FSC sets matching our FOB ownership criteria was used to estimate our Type I error as FSC sets should never be on a FOB; (2) the fraction of FOB sets meeting the conditions to be on an owned FOB based on matching vessel names, but failing to meet the separation distance condition was used to estimate the Type II error for this separation distance algorithm presuming that all matches meeting the vessel name condition are good matches; and (3) the fraction of FOB sets classified as being on foreign FOBs but meeting all conditions for being on an owned FOB except for not having a timestep $<=1$ hour was used to evaluate the validity of using this as a condition for FOB ownership. 


\subsection{Data treatments}

Preliminary analyses indicated that statistical analyses would benefit from removal of some outlier data. First, it was found that one $5^{\circ} \times 5^{\circ}$ grid cell centered on $62.5^{\circ} \mathrm{E}$ and $17.5^{\circ} \mathrm{N}$ contained only two anomalously-large fishing sets in a single year by a single vessel over the entire study time period. These two fishing sets were removed from the dataset.

Second, whereas most fishing vessels were active for the majority of the study time period, two vessels only fished in the Indian Ocean during 2010-2012 with low CPUE (Supplementary Table S1). Furthermore, very few of these sets were on FOBs with their own echosounder-equipped buoys, so data from these vessels was of little value for quantifying the effect of using echosounder buoys. Together the two boats represent $5.7 \%$ of the sets made between 2010 and 2017. It was therefore decided to remove these two vessels from the data.

\subsection{Statistical analyses}

Generalized Additive Models (GAMs), Generalized Linear Models (GLMs) and Beta regression models were developed to estimate the effect of having access to echosounder data on total catch and catch composition per successful set while controlling for potential sources of bias (see Table 1 for a full list of models). Catch per set was assumed to be Gamma distributed as this is a two-parameter positive definite distribution that is approximately normal for sufficiently small coefficient of variability. The proportion by weight of skipjack in a set was assumed to be Beta distributed, and binomial distributions were used to model the relative probability of a set being on a foreign FOB versus an owned FOB with echosounder as a function of set size category. Standard diagnostic plots of model residuals were used to assess the validity of these assumptions (Supplementary Figures S6-S11).

Six potential predictor variables were included in models:

- Category: Fishing set category $(F, O-E, O+E)$

- Vessel: A categorical variable for the vessel unique identifier to account for random 
variability among vessels in terms of fishing efficiency

- Year: A continuous variable from 0 to 7 corresponding to years 2010 to 2017

- Season: A categorical variable from 1 to 4 for 4 Monsoon-based climatic seasons

- Spatial parameters: $5^{\circ} \times 5^{\circ}$ cell for GLM and Beta regression models (cwp55); longitude (lon) and latitude (lat) for GAM models

- Size category: For modeling fishing set category as a function of set size (model N1), a categorical variable for set size with 5 tonne bins and a plus class for sets above 50 tonnes was used

First GAM model A1 (Table 1) was developed containing smooth terms for year by set category and for the interaction between longitude and latitude by season (all other predictors were not smoothed). This model was used to identify spatial and temporal non-linearity in catch per set, as well as identify temporal stability in the effect of set category on catch.

Based on the results of the first GAM model A1, GAM and GLM models were then developed for the latter years (2012-2017) of the dataset for which the effect of set category on catch was relatively constant over time (models A2 and L1, respectively). Given this constant effect, a single smooth for year was used in model A2 for all fishing set categories. GLM model L1 was included to confirm the robustness of results to model formalism and description of spatial variability.

GAM model A3 was developed to look at spatial inhomogeneity in the effect of fishing set category (and particularly $\mathrm{O}+\mathrm{E}$ data) on catch per set. In this model, the interaction between set category and space was studied by estimating a different smooth for longitude $\mathrm{x}$ latitude for each fishing set category and season combination.

Assuming that skipjack is the main target species for FAD-fishing, changes in the proportion of skipjack by set for the period 2010-2017 were examined using Beta regression (model B1). In this model, an interaction between set category and year was included to assess temporal changes in species composition as a function of set category. Orthogonal polynomials of the year predictor variable of up to $4^{\text {th }}$ order were used to account for non-linear temporal variability in skipjack proportion. 
Finally, to assess changes in the relative frequency of sets with different catch sizes when echosounders are in use, a binomial GAM model was developed with a categorical catch size variable with 5 tonnes bins and a plus size category for sets over 50 tonnes as a predictor and set category as the predicted variable (model N1). This model was limited to set categories $F$ and $O+E$.

Statistical analyses were carried out using R version 3.6.3 (2020-02-29) (R Core Team 2020). GAM models were estimated and visualized using the mgcv package version 1.8.33 (Wood 2011, 2020) and the mgcViz package version 0.1.6 (Fasiolo et al. 2020), respectively. Beta regression was done with the betareg package version 3.1.3 (Cribari-Neto \& Zeileis 2010).

[Table 1 about here.]

\section{Results}

\subsection{Accuracy of buoy ownership assignments}

The Type I error of our FOB ownership assignment methodology as assessed by the fraction of FSC sets, which should never truly be on an owned FOB, that nevertheless meet the conditions for being considered to be on an owned FOB was $4.8 \%$ out of 6065 FSC sets examined.

The Type II error of the set-trajectory separation distance condition for being considered to be on an owned FOB was assessed by estimating the fraction of FOB sets meeting the ownership conditions based on matching vessel names (and, therefore, considered to be a good assignment) that fail to meet the separation distance condition. $15.8 \%$ of the 2610 FOB sets classified as on owned FOBs based on matching vessel names fall into this cateogry. Though larger than the overall Type I error, it is important to note that only $1.1 \%$ of the 7418 FOB sets classified as foreign do meet the base conditions of having a nearby (i.e., $<=11 \mathrm{~km}$ ) buoy trajectory with at least 2 days of trajectory data over the 5 days preceding the set, $90 \%$ of which is classified in the water, and a minimum timestep $<=1$ hour. Therefore, this error only applies to a small percentage of the data. 
Finally, only $0.5 \%$ of the potential FOB set-buoy trajectory matches that have matching vessel names and meet the base conditions for being a good match (e.g., 2 days of in water trajectory data) have a minimum timestep greater than 1 hour. This indicates that French purse seiners essentially always reduce the emission frequency of buoys when they approach a FOB, supporting the imposition of this condition for considering a FOB set to be on an owned FOB.

\subsection{Preliminary analyses}

[Figure 1 about here.]

[Figure 2 about here.]

[Figure 3 about here.]

[Figure 4 about here.]

There were no consistent differences between the proportions of null FOB sets for the three set categories (Figure 1; no significant differences between set categories found by a binomial GLM). The percentage of null sets generally varied between $6 \%$ and $10 \%$ for all three set categories except for a couple of year-category combinations for which very little data was available (e.g., 2014 O-E; Figure 1).

In each of the three set categories, the number of FOB sets has varied considerably over years (Figure 2). Though the proportion of (positive) FOB sets for which vessel's had access to buoy tracking information was $\approx 25-30 \%$ in the early part of the time series, this proportion has increased dramatically since 2015 , reaching $\approx 50 \%$ in 2017 . This change is entirely due to a large increase in the number of sets on the vessel's own echosounder-equipped buoys (solid curve in Figure 2a). The use of buoys without echosounders decreased steadily over the time series, disappearing entirely after 2014 (dotted curve in Figure 2a). It must be noted that the number of FOB sets per vessel per year did not show strong or consistent pattern despite variations over the study period (Figure 3). The number of FOB sets appears to be marginally higher for 2010, coincident 
with the impacts of Somali piracy on the fishery, and for 2016-2017, coincident with both a gradual shift away from fishing on free schools after 2014 (not shown) and the imposition of a quota on yellowfin tuna in 2017 that led to increased fishing on FOBs. The increase in the total number of FOB sets in the Indian Ocean (Figure 2a) was, therefore, primarily due to the entry into the fishery of five vessels in 2014 (Supplementary Tables S1 to S3). Mean catch per set varied over years between 22 and 31 tonnes for all year-set category combinations for which reasonable amounts of data are available (Figure 4; median values in Supplementary Figure S1). From 2012 onward, mean catch for $O+E$ sets is consistently higher than that for $F$ sets, averaging 2.6 tonnes more catch per set. This corresponds to a $10.6 \%$ increase in catch per set for $O+E$ sets over $F$ sets.

[Figure 5 about here.]

Though catch species composition was globally similar between the different set categories, there does appear to be an interaction between set category, species composition and year (Figure 5). Over the study time period, the fraction of skipjack in $O+E$ sets increased relative to that of $F$ sets, being initially lower than that for $F$ sets, but eventually surpassing that of $F$ sets (solid versus dashed curves in Figure 5a). Conversely, the fraction of yellowfin decreased over time for $O+E$ sets relative to that of $F$ sets (solid versus dashed curves in Figure 5b).

With the objective of identifying any potential interaction between set category and the area explored by fishers, we analyzed the spatial distribution of sets for each set category (Supplementary Figure S4). Though there is interannual variability in the spatial distribution of fishing sets, there is no clear evidence of consistent differences in the spatial distributions of sets between set categories. Apart from the disappearance of $O-E$ sets after 2015, results for all time period-set category combinations have approximately the same overall spatial extent and similar relative densities of sets per cell. This is also true for median catch per set (Supplementary Figure S5). 


\subsection{Statistical analysis}

In order to eliminate the possibility that observed differences in catch per set with and without access to echosounder data are due to spatial, seasonal or fishing vessel differences between $F$ and $O+E$ sets, we ran a series of GAM and GLM statistical models including these variables in addition to set category (see Table 1 for details). Results from the initial GAM model A1 based on the entire 2010-2017 time series indicate that all of these factors have a significant impact on catch per set (Table 2). In particular, though there is interannual variability in catch per set as a function of the set category, catch per $O+E$ set is relatively stable after $\approx 2012$ (Figure 6 ). We, therefore, used the time period 20122017 for all other models except model B1 used to assess change in skipjack proportion in the catch per set.

[Table 2 about here.]

[Figure 6 about here.]

[Table 3 about here.]

Results for GAM model A2 and GLM model L1 for the period 2012-2017 were consistent with exploratory analyses, indicating a significant increase in catch per successful set of approximately 2.0 to 2.5 tonnes per $O+E$ set relative to $F$ sets (see the coefficient of the $O+E$ terms in Table 3). Spatial, temporal and vessel terms did explain significant variance in catch per set (Supplementary Tables S4 and S6).

[Figure 7 about here.]

The interaction between the set category and spatial zone (model A3) was seasonally variable and relatively weak over much of the core purse-seine fishing grounds (Figure 7). Nevertheless, catch per $O+E$ set tended to be larger than that for $F$ sets in the core FOB fishing areas east of Somalia for seasons 1 and 4 and east of Tanzania for season 2 , and the reverse is true for the zone east of Tanzania for season 1 . Patterns are more complex and variable for other seasons and zones (specificaly areas less explored by the French purse seiners). 
Beta regression model B1 confirmed that even after accounting for spatial and vessel differences, there was a significant interaction between year and set category on the proportion of catch that is skipjack (Table 4), with the skipjack proportion increasing over time for $O+E$ sets relative to $F$ sets.

[Figure 8 about here.]

The use of FOBs equipped with echosounder buoys has also significantly changed the set size distribution. Binomial GAM model N1 indicates that $O+E$ sets since 2012 have a small proportion of sets below the mean set size of $\approx 25$ tonnes relative to $F$ sets and a large proportion of sets above this size (Figure 8). The transition from negative to positive differences is abrupt, suggestive of a threshold effect for the impact of having access to echosounder data on catch per set.

\section{Discussion}

Our results convincingly demonstrate how and when the use of echosounder buoys information has increased catch per FOB set in the French Indian Ocean tropical tuna purse-seine fishery. Sets on FOBs for which fishers have access to echosounder data catch on average $\approx 2.0-2.5$ tonnes more tuna than sets on FOBs for which fishers do not have this information, either because the tracking buoy does not belong to the vessel or because the tracking buoy does not have an integrated echosounder. This increase corresponds to an approximately $10 \%$ increase in catch per set. Catch per set on FOBs with echosounder buoys is fairly consistent after 2012. Before 2012, there is evidence of a period during which French purse seiner skippers appear to have been learning how to take advantage of buoy echosounder data, though this period is also coincident with improvements in buoy echosounder technology that may have played a role. Though a $10 \%$ increase in catch may seem relatively moderate, 2.0-2.5 tonnes of tuna has an approximate cannery 
sale value of US\$2200-2800. ${ }^{1}$ Given that a buoy is used on average 3 or 4 times before being lost or retired, the gains far outweigh the cost of an echosounder buoy $(\approx$ US $\$ 1000$ 1500; Lopez et al. 2014) by approximately US\$5000-7000. Furthermore, echosounder buoys also likely represent a gain in search time as they permit remotely determining the presence or absence of a tuna school under a FOB (Baidai et al. 2020). This gain may increase over time due to advances in research. For example, based on differences in the acoustic response between skipjack and bigeye, Moreno et al. (2019) highlighted the interest of predicting the species proportion in the tuna school for tuna conservation.

The use of echosounder-equipped tracking buoys is coincident with an increase in the proportion of FOB sets on buoys to which the vessel has access to tracking and echosounder information. The proportion of sets directed at a vessel's own FOBs and the increasing trend in this proportion are consistent, though on the high end, of prior, more approximate estimates of FOB fishing strategy (Snouck-Hurgronje et al. 2018). This increasing trend highly suggests that the benefits of using this technology have been sufficient to cause fishers to change fishing strategy from one in which random encounters of foreign FOBs and free schools were important components of overall fishing effort to a strategy increasingly directed towards the vessel's own FOBs for which the fisher has access to echosounder information. The potential contribution of this change to the recent increase in dFAD deployments (Lopez et al. 2017, Imzilen et al. 2020) is an important avenue for future research.

Increases in catch per set when using echosounder buoys occur in a non-linear fashion consistent with a threshold detection effect for fish schools. When using echosounder buoys, skippers tend not to set on small schools less than $\approx 20-25$ tonnes which results in an increase in the number of sets catching more than this amount, with a rapid, nonlinear transition between these two states (Figure 8). Prior analyses have shown that echosounder buoys are effective at detecting presence of fish schools above this size, but provide only relatively weak information on the absolute size of fish schools (Baidai et al. 2020). Our results are consistent with these observations, showing relatively homogeneous

\footnotetext{
${ }^{1}$ https://www.undercurrentnews.com/data/prices/\#/skipjack_seychelles\&start $=0 \& e n d=5 ; \quad$ the value quoted is an approximate mean for the period September 2019-February 2020
} 
changes in the relative frequency of sets above and below this set size, with a narrow transition between the two school size categories.

We do not have a clear explanation for the observed increase in the relative proportion of skipjack in $O+E$ FOB catches over time. One hypothesis is that as fishers became more accustomed to the new technology, they gradually became more efficient at identifying large schools of skipjack tuna, the primary target for FOB fishing. Recent concern regarding the status of yellowfin stocks in the Indian Ocean may also play a role, though the timing is off with concern increasing after about 2016 and a yellowfin quota being imposed in 2017. This trend merits further examination in future research, e.g., by comparison with results for the Atlantic Ocean and other purse seine fleets.

Though we did not observe strong spatial inhomogeneities in the core zone of purse seine fishing with respect to the impact of echosounder buoys on catch per set, there are hints of regional trends in the effectiveness of this technology for detecting fish schools. Catch on echosounder-equipped buoys belonging to the fishing vessel appears to be higher in vicinity of the Somali upwelling zone and lower in the northern Mozambique Channel and off Tanzania. These two areas are quite different in terms of productivity, fishing season and fishing strategy. Monsoon-driven upwelling off Somalia, roughly occurring from July to October, sustains essential nursery habitat for all species of tropical tuna (Kaplan et al. 2014). During this season, fishers concentrate the vast majority of their effort in this area and echosounder buoys appear to be highly effective at increasing FOB catch rates. By contrast, the Mozambique Channel is an important area for both FOB and free school fishing somewhat earlier in the year (March-June) (Kaplan et al. 2014). This area is characterized by eddy circulation and increased turbid due to river outflows (Schott et al. 2009). The interaction between anticyclonic and cyclonic eddies generates high dynamical and complex barriers consisting of multiple fronts at different scales favorable to the production and aggregation of organic matter (Tew-Kai \& Marsac 2009). This region is also characterized by a relatively high rate of occurrence of natural FOBs (Maufroy et al. 2015). Though it is unclear exactly how these regional differences might impact the effectiveness of echosounder buoys, we speculate that water turbidity 
and stability of environmental conditions may impact both the quality of the echosounder signal and fishers capacity to accurately interpret echosounder data.

Our results have significant consequences for stock assessment. FOB catches provide important data for estimating the trend in abundance of skipjack tuna and juvenile population sizes for yellowfin and bigeye tuna. The recent use of echosounder buoys is likely to cause positive bias in nominal CPUE series, potentially contributing to hyperstability and failure to detect overexploitation if this bias is not properly accounted for. For example, using predictions from model A2 where we have artificially standardized all sets to be category $F$, we estimate that the use of echosounders increased total FOB catch by the French fleet between $1.7 \%$ and $4.0 \%$ per year over the period 2012-2017. Though relatively small, this amount could be critical for the management of fully exploited tuna species. Furthermore, the impact of echosounders is likely to grow over time as purse seiners increasingly target their own FOBs and echosounder technology improves, highlighting the importance of accounting for these changes.

The question is how to apply this knowledge to the standardization of CPUE data for the ensemble of tropical tuna purse seine fleets. Ideally, one would collect data on the provenance and characteristics of FOBs associated with fishing sets and directly integrate this information into CPUE standardization models. Though fleets are beginning to collect more data on FOB use, this data will likely never be available for historical data and may not directly address questions of buoy ownership. Back calculating ownership using FOB tracking buoy trajectories as we have done in this paper is a possibility, but, for example, the Spanish purse-seine fleet began using echosounder buoys in the 2000's (Lopez et al. 2014) long before trajectory data were regularly saved and made available to scientists. Nevertheless, if mean data per fleet, ocean and year on the probability of fishing on a FOB equipped with echosounder buoys can be obtained (for example, by extrapolating from know fleet purchases of echosounder buoys and recent estimates of the rate of fishing on owned FOBs), then applying a constant negative corrective factor to all FOB catches may be the best available solution given the relatively consistent impact of echosounder buoys on catch per set over the period of our study ( $\approx 2.0$ tonnes per set). 
Though we consider that our results are approximately applicable to all purse-seine fishing fleets, and in particular the Spanish and Seychelles fleets, ideally this would be validated by carrying out similar analyses for each fleet. The Spanish fleet currently uses a wider variety of buoy models and manufacturers (Lopez et al. 2016), and the extent to which technological differences between different buoy models impacts the effectiveness of echosounder information for identifying large fishing schools is currently poorly understood. We, therefore, hope that these analyses can be carried out in the near future, though data access limitations and lack of historical data for the Spanish fleet may represent significant barriers. In the absence of these analyses, our results represent the best available data regarding the impact of this important technological change on purse seine catch per set and we strongly encourage integration of our results in future stock assessments.

\section{Supplementary material}

Supplementary material is available at the ICESJMS online version of the manuscript. The document includes analyses complementary to those of the article, as well as the diagnostic plots of the models used.

\section{Data availability statement}

Given the confidential nature of the data used in this paper, requests for data access should be addressed directly to the Ob7 (https://www.ob7.ird.fr/en/) pelagic ecosystem observatory using the following email address: adm-dblp@ird.fr.

\section{$7 \quad$ Funding}

This work was funded by the European project SC14 under the Framework Contract Safewaters2 (EASME/EMFF/008). 


\section{References}

Ariz J, Delgado De Molina A, Fonteneau A, Gonzales Costas F, Pallarés P (1999) Logs and tunas in the Eastern Tropical Atlantic. A review of present knowledge and uncertainties. Proceedings of the International Workshop on Fishing For Tunas Associated with Floating Objects. IATTC Special Report, 11: 21-65.

Baidai Y, Dagorn L, Amande MJ, Gaertner D, Capello M (2020) Machine learning for characterizing tropical tuna aggregations under Drifting Fish Aggregating Devices (DFADs) from commercial echosounder buoys data. Fisheries Research 229. doi:10.1016/j.fishres.2020.105613

Bishop J (2006) Standardizing fishery-dependent catch and effort data in complex fisheries with technology change. Reviews in Fish Biology and Fisheries 16:21-38. doi:10.1007/s11160006-0004-9

Cribari-Neto F, Zeileis A (2010) Beta regression in R. Journal of Statistical Software 34:1-24

Escalle L, Gaertner D, Chavance P, Delgado De Molina A, Ariz J, Mérigot B (2017) Forecasted consequences of simulated FAD moratoria in the Atlantic and Indian Oceans on catches and bycatches. ICES Journal of Marine Science 74:780-792. doi:10.1093/icesjms/fsw187

Fasiolo M, Nedellec R, Goude Y, Wood SN (2020) Scalable Visualization Methods for Modern Generalized Additive Models. Journal of Computational and Graphical Statistics 29:78-86. doi:10.1080/10618600.2019.1629942

Filmalter JD, Capello M, Deneubourg J-L, Cowley PD, Dagorn L (2013) Looking behind the curtain: Quantifying massive shark mortality in fish aggregating devices. Frontiers in Ecology and the Environment 11:291-296. doi:10.1890/130045

Fonteneau A, Gaertner D, Nordström V (1999) An overview of problems in the CPUEabundance relationship for the tropical purse seine fisheries. ICCAT, 49(3): 259-276.

Fonteneau A, Chassot E, Bodin N (2013) Global spatio-temporal patterns in tropical tuna purse seine fisheries on drifting fish aggregating devices (DFADs): Taking a historical perspective to inform current challenges. Aquatic Living Resources 26:3748. doi:10.1051/alr/2013046 
Gaertner D, Pallarés P (2002) The European Union Research Project, Efficiency of Tuna Purse-Seiners and Effective Effort (ESTHER): Scientific report of project. Doc. SCTB15-FTWG-3.

Gaertner D, Ariz J, Bez N, Moreno G, Murua H, Soto M, Marsac F (2016) Results achieved within the framework of the EU research project: Catch, Effort, and eCOsystem impacts of FAD-fishing (CECOFAD). IOTC-2016-WPTT18-35.

Hallier JP, Gaertner D (2008) Drifting fish aggregation devices could act as an ecological trap for tropical tuna species. Marine Ecology Progress Series 353:255-264. doi:10.3354/meps07180

Hallier JP, Parajua JI (1999) Review of tuna fisheries on floating objects in the Indian Ocean. Proceedings of the International Workshop on Fishing For Tunas Associated with Floating Objects. IATTC Special Report, 11 : 195-221.

ICCAT (2016) Recommendation by ICCAT on a multi-anual conservation and management programme for tropical tunas. Rec 16-01.

Imzilen T, Lett C, Chassot E, Kaplan DM (2020) Spatial management can significantly reduce dFAD beachings in Indian and Atlantic Ocean tropical tuna purse seine fisheries. bioRxiv:2020.11.03.366591. doi:10.1101/2020.11.03.366591

Kaplan DM, Chassot E, Amandé JM, Dueri S, Demarcq H, Dagorn L, Fonteneau A (2014) Spatial management of Indian Ocean tropical tuna fisheries: Potential and perspectives. ICES Journal of Marine Science: Journal du Conseil 71:1728-1749. doi:10.1093/icesjms/fst233

Lopez J, Moreno G, Sancristobal I, Murua J (2014) Evolution and current state of the technology of echo-sounder buoys used by Spanish tropical tuna purse seiners in the Atlantic, Indian and Pacific Oceans. Fisheries Research 155:127-137. doi:10.1016/j.fishres.2014.02.033

Lopez J, Moreno G, Boyra G, Dagorn L (2016) A model based on data from echosounder buoys to estimate biomass of fish species associated with fish aggregating devices. Fishery Bulletin 114:166-178. doi:10.7755/FB.114.2.4

Lopez J, Moreno G, Ibaibarriaga L, Dagorn L (2017) Diel behaviour of tuna and non-tuna species at drifting fish aggregating devices (DFADs) in the Western Indian Ocean, de- 
termined by fishers' echo-sounder buoys. Marine Biology 164:1-16. doi:10.1007/s00227017-3075-3

Marchal P, Andersen B, Caillart B, Eigaard O, Guyader O, Hovgaard H, Iriondo A, Le Fur F, Sacchi J, Santurtún M (2007) Impact of technological creep on fishing effort and fishing mortality, for a selection of European fleets. ICES Journal of Marine Science 64:192-209. doi:10.1093/icesjms/fsl014

Maufroy A, Chassot E, Joo R, Kaplan DM (2015) Large-Scale Examination of SpatioTemporal Patterns of Drifting Fish Aggregating Devices (dFADs) from Tropical Tuna Fisheries of the Indian and Atlantic Oceans. PLoS ONE 10:e0128023. doi:10.1371/journal.pone.0128 Maunder MN, Punt AE (2004) Standardizing catch and effort data: A review of recent approaches. Fisheries Research 70:141-159. doi:10.1016/j.fishres.2004.08.002

Moreno G, Boyra G, Sancristobal I, Itano D, Restrepo V (2019) Towards acoustic discrimination of tropical tuna associated with Fish Aggregating Devices. PLoS ONE 14:1-24. doi:10.1371/journal.pone.0216353

Pianet R, Pallarés P, Petit C (2000) New sampling and data processing strategy for estimating the composition of catches by species and sizes in the European purse seine tropical tuna fisheries. IOTC Proceedings no. 3 page 104-139.

R Core Team (2020) R: A language and environment for statistical computing. R Foundation for Statistical Computing, Vienna, Austria. Available from: https://www.Rproject.org/

Robins CM, Wang YG, Die D (1998) The impact of global positioning systems and plotters on fishing power in the northern prawn fishery, Australia. Canadian Journal of Fisheries and Aquatic Sciences 55:1645-1651. doi:10.1139/f98-037

Schott FA, Xie S-P, McCreary Jr. JP (2009) Indian ocean circulation and climate variability. Reviews of Geophysics 47:1-46. doi:10.1029/2007RG000245

Snouck-Hurgronje JE, Kaplan DM, Chassot E, Maufroy A, Gaertner D (2018) Fishing on floating objects (FOBs): How French tropical tuna purse seiners split fishing effort between GPS-monitored and unmonitored FOBs. Canadian Journal of Fisheries and Aquatic Sciences 75:1849-1858. doi:10.1139/cjfas-2017-0152 
Tew-Kai E, Marsac F (2009) Patterns of variability of sea surface chlorophyll in the Mozambique Channel: A quantitative approach. Journal of Marine Systems 77:7788. doi:10.1016/j.jmarsys.2008.11.007

Torres-Irineo E, Gaertner D, Chassot E, Dreyfus-León M (2014) Changes in fishing power and fishing strategies driven by new technologies: The case of tropical tuna purse seiners in the eastern Atlantic Ocean. Fisheries Research 155:10-19. doi:10.1016/j.fishres.2014.02.017

Ward P (2008) Empirical estimates of historical variations in the catchability and fishing power of pelagic longline fishing gear. Reviews in Fish Biology and Fisheries 18:409426. doi:10.1007/s11160-007-9082-6

Wood S (2020) Mgcv: Mixed gam computation vehicle with automatic smoothness estimation. Available from: https://CRAN.R-project.org/package=mgcv

Wood SN (2011) Fast stable restricted maximum likelihood and marginal likelihood estimation of semiparametric generalized linear models. Journal of the Royal Statistical Society (B) 73:3-36

\section{Acknowledgements}

We thank ORTHONGEL for making their FOB tracking data available and the IRDOb7 pelagic observatory of the MARBEC laboratory for tropical tuna logbook, observer and trajectory data management and preparation, particularly L. Floch. We thank F. Marsac, V. Aragno, L. Dagorn, Y. Baidai and M. Capello for many helpful suggestions regarding our analyses, as well as the handling editor and two anonymous reviewers for their very constructive comments that greatly improved the manuscript. 


\section{${ }_{616}$ List of Tables}

6171 Models used to estimate the impact of echosounder buoys on catch of major

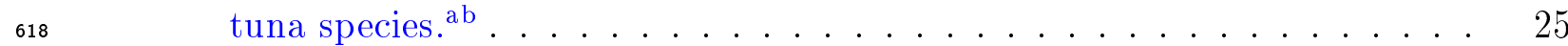

${ }_{619} 2$ ANOVA table for a series of nested GAM models culminating in model A1. ${ }^{\mathrm{a}} 26$

${ }_{620} 3$ Regression coefficients related to set category for GAM model A2 and GLM

${ }_{621}$ model L1. ${ }^{\mathrm{a}} \ldots \ldots \ldots \ldots \ldots \ldots \ldots \ldots$

${ }_{622} 4$ Regression coefficients related to set category and year for Beta model B1. ${ }^{\text {ab }} 28$ 
Table 1: Models used to estimate the impact of echosounder buoys on catch of major tuna species. ${ }^{\text {ab }}$

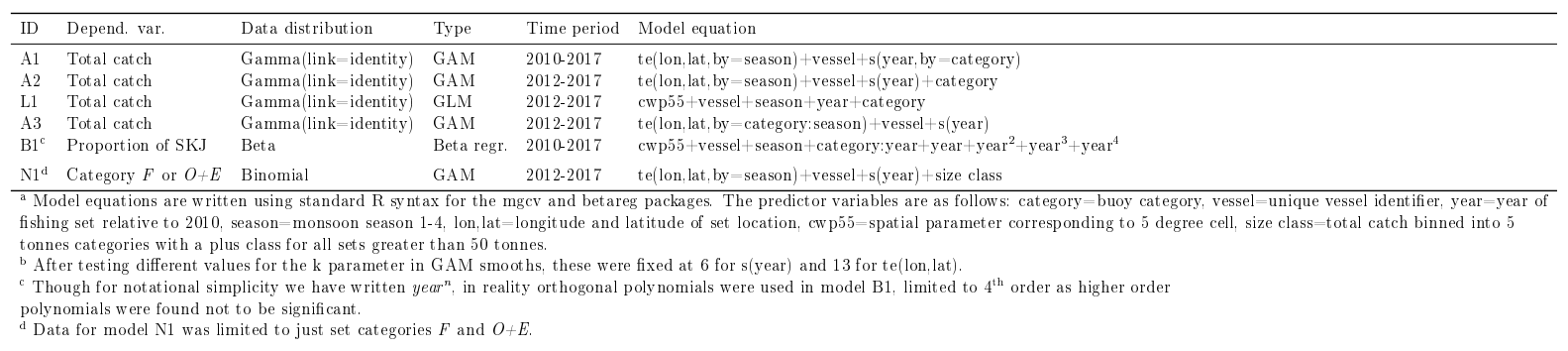


Table 2: ANOVA table for a series of nested GAM models culminating in model A1. ${ }^{\mathrm{a}}$

\begin{tabular}{lrrrrrl}
\hline & Resid. Df & Resid. Dev & Df & Deviance & $\operatorname{Pr}(>$ Chi $)$ & \\
\hline NULL & 10265 & 8282 & & & & \\
te(lon,lat,by=season) & 10008 & 7585 & 257.47 & 697.4 & 0.0000 & $* * *$ \\
vessel & 9992 & 7553 & 15.83 & 31.5 & 0.0023 & $* *$ \\
s(year,by=category) & 9973 & 7482 & 19.18 & 71.2 & 0.0000 & $* * *$ \\
\hline
\end{tabular}

${ }^{\mathrm{a}}$ See Table 1 for model details. 
Table 3: Regression coefficients related to set category for GAM model A2 and GLM model L1.

\begin{tabular}{lrrrrrrrr}
\hline & \multicolumn{3}{c}{ GAM Model A2 } & & \multicolumn{3}{c}{ GLM Model L1 } \\
\cline { 2 - 3 } \cline { 6 - 8 } & Estimate & $\operatorname{Pr}(>|\mathrm{t}|)$ & & Estimate & $\operatorname{Pr}(>|\mathrm{t}|)$ & \\
\hline Intercept $($ Cat. $F)$ & 22.00 & 0.0000 & $* * *$ & & 21.7 & 0.0000 & $* * *$ \\
Category $O-E$ & -2.26 & 0.2241 & & 0.2 & 0.9253 & \\
Category $O+E$ & 1.98 & 0.0001 & $* * *$ & & 2.5 & 0.0000 & $* * *$ \\
\hline
\end{tabular}

${ }^{a}$ See Table 1 for model details. 
Table 4: Regression coefficients related to set category and year for Beta model B1. ${ }^{\mathrm{ab}}$

\begin{tabular}{lrrl}
\hline & Estimate & $\operatorname{Pr}(>\mathrm{z})$ & \\
\hline Intercept (Cat. $F)$ & 0.05 & 0.5701 & \\
Year & 7.14 & 0.0000 & $* * *$ \\
Year $^{2}$ & 6.59 & 0.0000 & $* * *$ \\
Year $^{3}$ & -7.76 & 0.0000 & $* * *$ \\
Year $^{4}$ & -1.52 & 0.0935 & $\cdot$ \\
Category $O-E$ & 0.08 & 0.4796 & \\
Category $O+E$ & 0.00 & 0.8112 & \\
Year : Category $O-E$ & 2.82 & 0.7120 & \\
Year : Category $O+E$ & 15.39 & 0.0000 & $* * *$ \\
\hline
\end{tabular}

${ }^{\mathrm{a}}$ See Table 1 for model details.

b Though for simplicity we use the notation of raw polynomial terms, the Year $^{n}$ terms actually

represent $n^{\text {th }}$ order orthogonal polynomials. 


\section{List of Figures}

1 Proportion of null FOB sets from 2010 to 2017 for each set category. The set categories are: $F=$ foreign FOB; $O-E=$ owned buoy without echosounder;

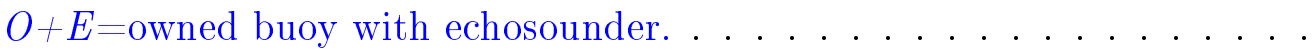

2 Absolute number of positive FOB sets for each set category (a) and the proportion of all positive FOB sets that are in each category (b) for the period 2010-2017. The set categories are: $F=$ foreign FOB; $O-E=$ owned buoy without echosounder; $O+E=$ owned buoy with echosounder. In (b), the proportions are cumulative with $O+E$ representing the proportion of sets on owned buoys possessing echosounders and $O$ indicating the total proportion of sets on owned buoys with and without echosounders. The proportion that $F$ sets represents is one minus that for $O$ sets. Note that there were no $O+E$ sets in 2010, and from 2015 onward there were no $O-E$

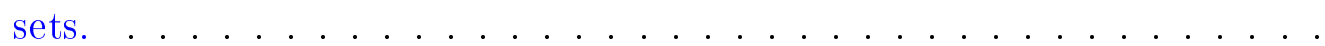

3 Boxplots of the number of FOB sets per vessel per year. Boxplots only include vessels for which at least one set was carried out in the given year. Whiskers on the boxplot represent the extremes for the given year. . . . .

4 Mean catch per set between 2010 and 2017 for each of the three set categories. The set categories are: $F=$ foreign FOB; $O-E=$ owned buoy without echosounder; $O+E=$ owned buoy with echosounder. . . . . . . . .

5 Average proportion of catch in each of the three major species of tunas as a function of set category and year. The tuna species are (a) SKJ=skipjack, (b) YFT=yellowfin and (c) BET=bigeye. The set categories are: $F=$ foreign FOB; $O-E=$ owned buoy without echosounder; $O+E=$ owned buoy with echosounder. . . . . . . . . . . . . .

6 Effect of the interaction between year and set category estimated from GAM model A1 (see Table 1). The panels are from top to bottom: (a) $F=$ foreign FOB; (b) $O-E=$ owned buoy without echosounder; (c) $O+E=$ owned buoy with echosounder. Vertical red lines indicate the range of years for which we have data for the set category corresponding to a given panel. . Difference between the smoothed spatial effects for fishing set categories $F$ and $O+E$ for each season from GAM model A3 (see Table 1). Colors indicate the difference between the two effects in tonnes, with positive values indicating higher catch per set for $O+E$ sets. Differences have been constrained to the range -30 to 30 tonnes so as to avoid anomalously large predictions in areas with little data (i.e., dark blue and bright yellow regions in peripheral areas for some reasons). Black solid and dotted contour lines indicate differences of +5 and -5 tonnes, respectively. Red solid and dotted contour lines indicate significant differences at the 0.05 and 0.01 level, respectively, as determined by the plotDiff function of the mgcViz

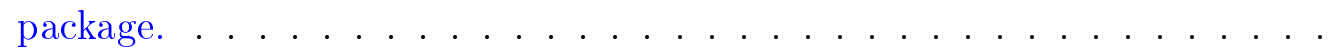


8 Relative probability of sets being of type $F$ versus $O+E$ as a function of set catch size category for data from 2012-2017. Results show the coefficients of the terms corresponding to the different catch size categories in model N1 (see Table 1). Positive values along the y-axis indicate that a set of a given size is more likely to be of category $O+E$ than category $F$. As we are only concerned with relative probabilities, coefficients have been centered by removing the mean of all the coefficients. Note that the final size category is a plus class containing all sets greater than 50 tonnes. . . 


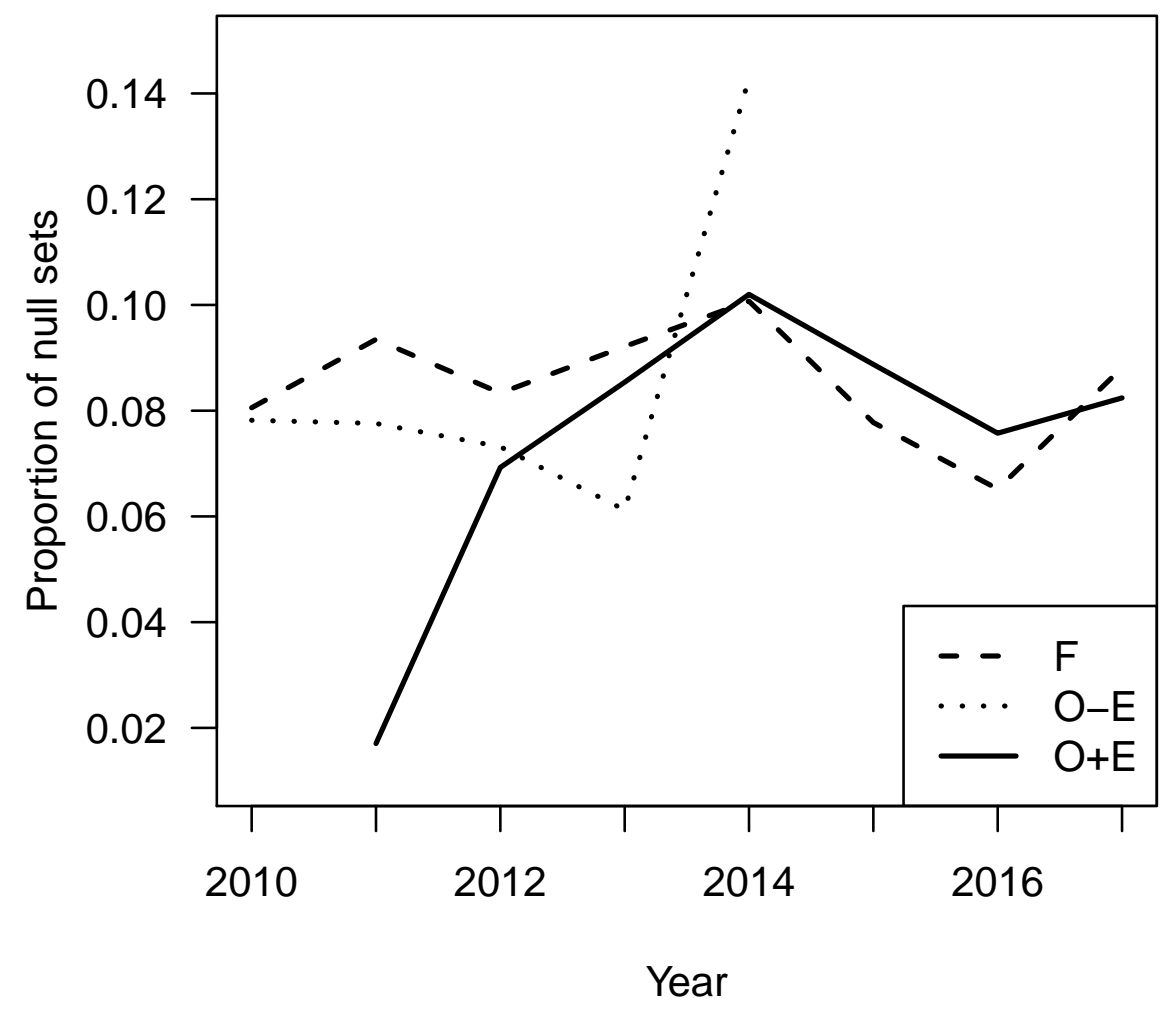

Figure 1: Proportion of null FOB sets from 2010 to 2017 for each set category. The set categories are: $F=$ foreign FOB; $O-E=$ owned buoy without echosounder; $O+E=$ owned buoy with echosounder. 

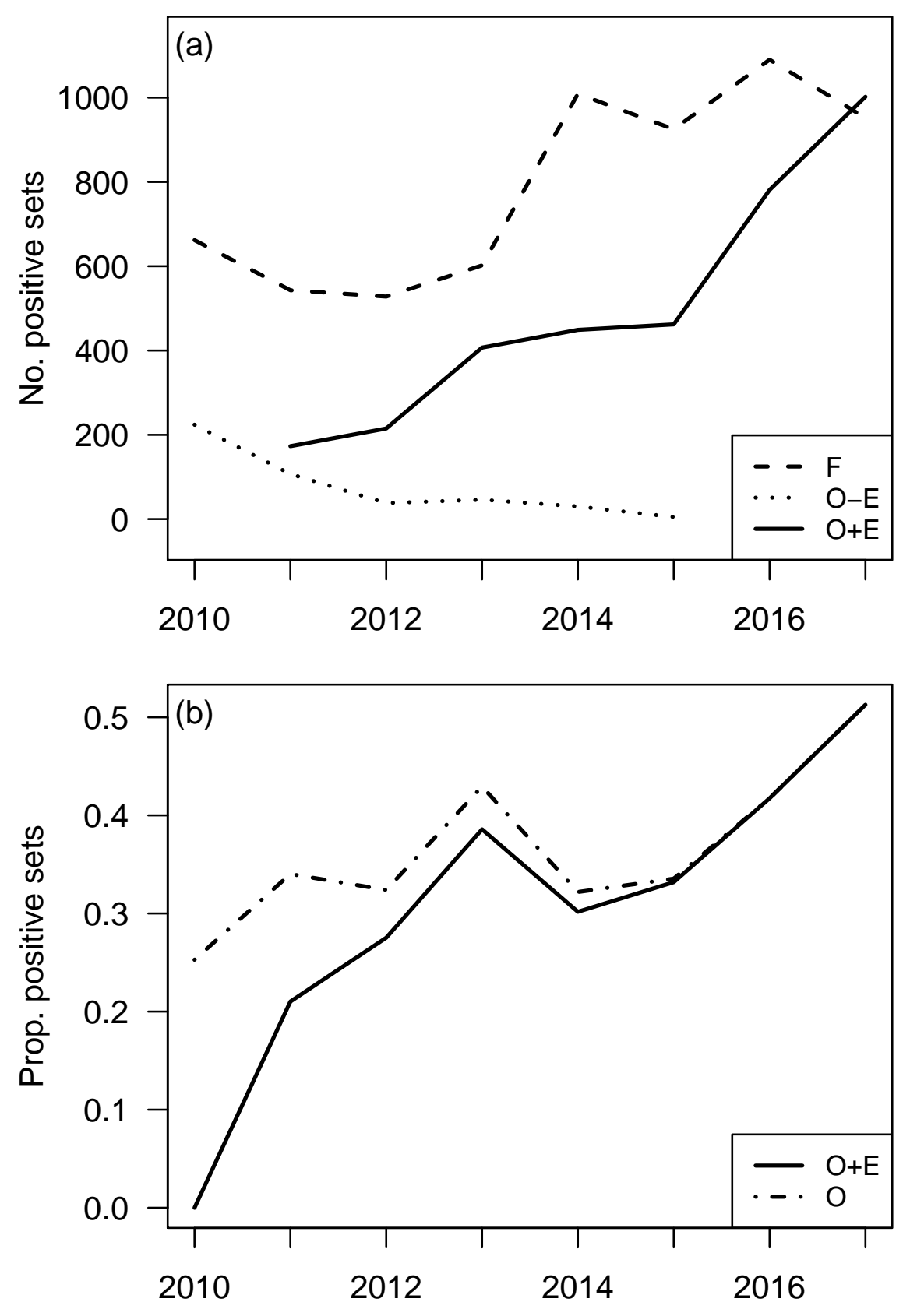

Year

Figure 2: Absolute number of positive FOB sets for each set category (a) and the proportion of all positive FOB sets that are in each category (b) for the period 2010-2017. The set categories are: $F=$ foreign FOB; $O-E=$ owned buoy without echosounder; $O+E=$ owned buoy with echosounder. In (b), the proportions are cumulative with $O+E$ representing the proportion of sets on owned buoys possessing echosounders and $O$ indicating the total proportion of sets on owned buoys with and without echosounders. The proportion that $F$ sets represents is one minus that for $O$ sets. Note that there were no $O+E$ sets in 2010, and from 2015 onward there were no $O-E$ sets. 


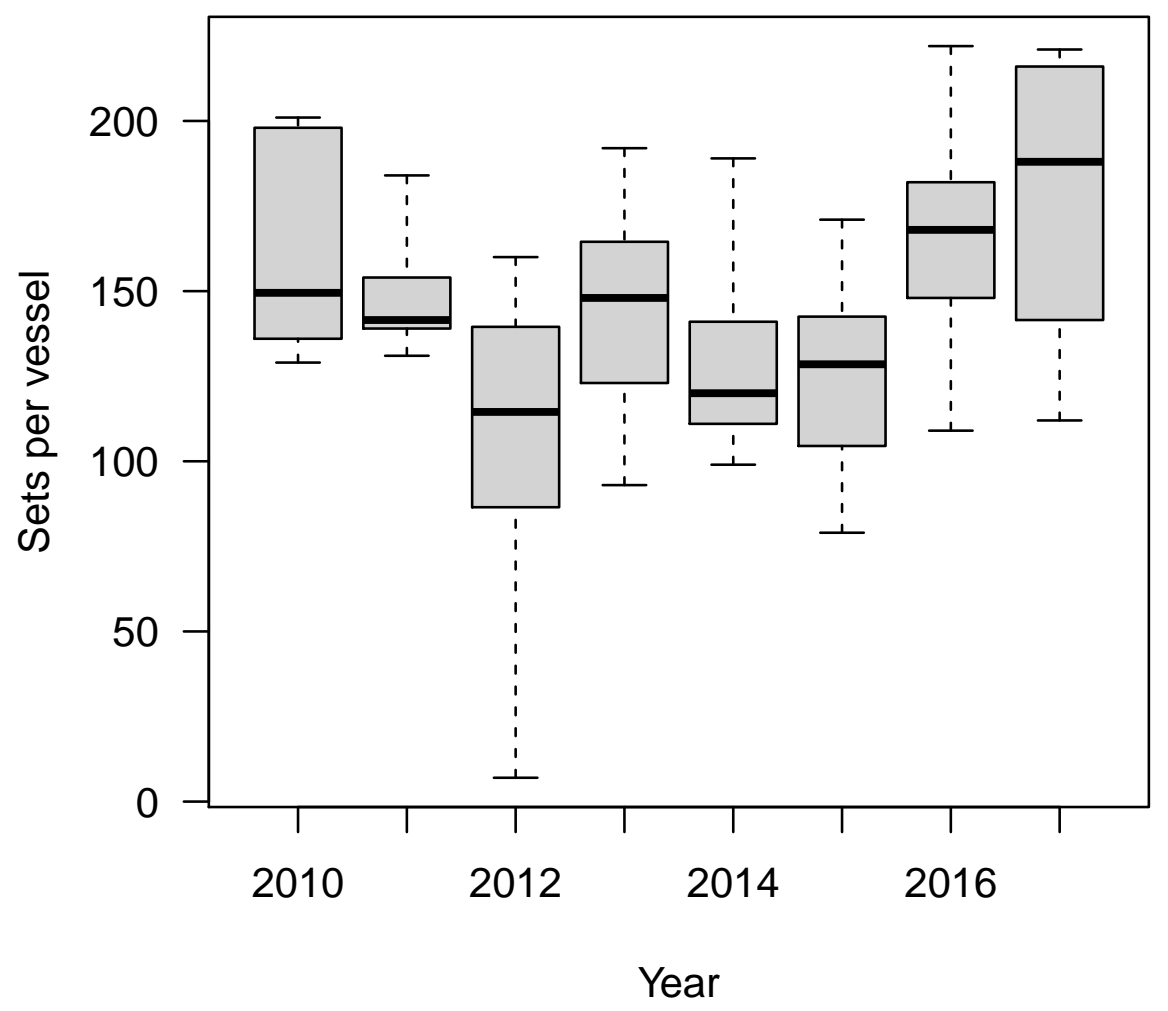

Figure 3: Boxplots of the number of FOB sets per vessel per year. Boxplots only include vessels for which at least one set was carried out in the given year. Whiskers on the boxplot represent the extremes for the given year. 


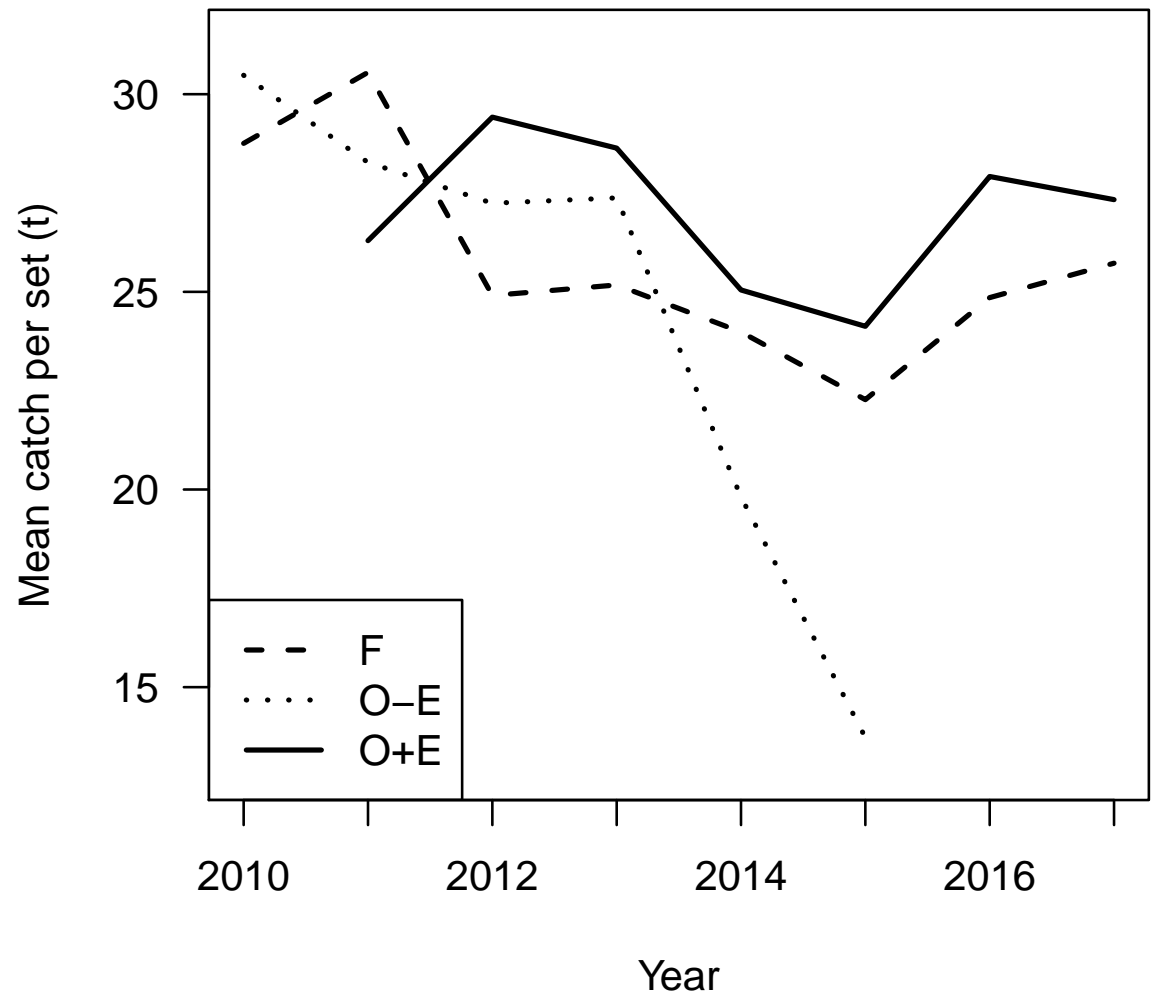

Figure 4: Mean catch per set between 2010 and 2017 for each of the three set categories. The set categories are: $F=$ foreign FOB; $O-E=$ owned buoy without echosounder; $O+E=$ owned buoy with echosounder. 
(a) SKJ

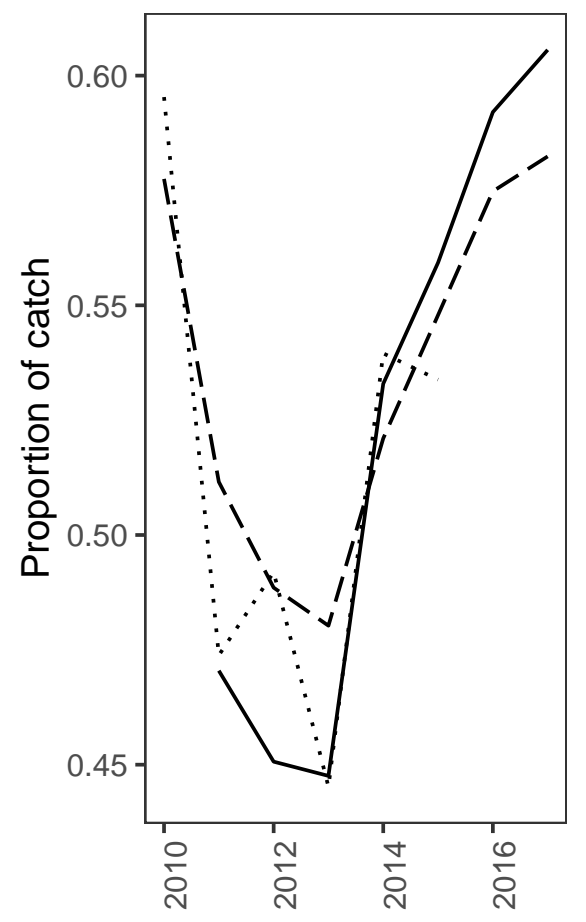

(b) YFT

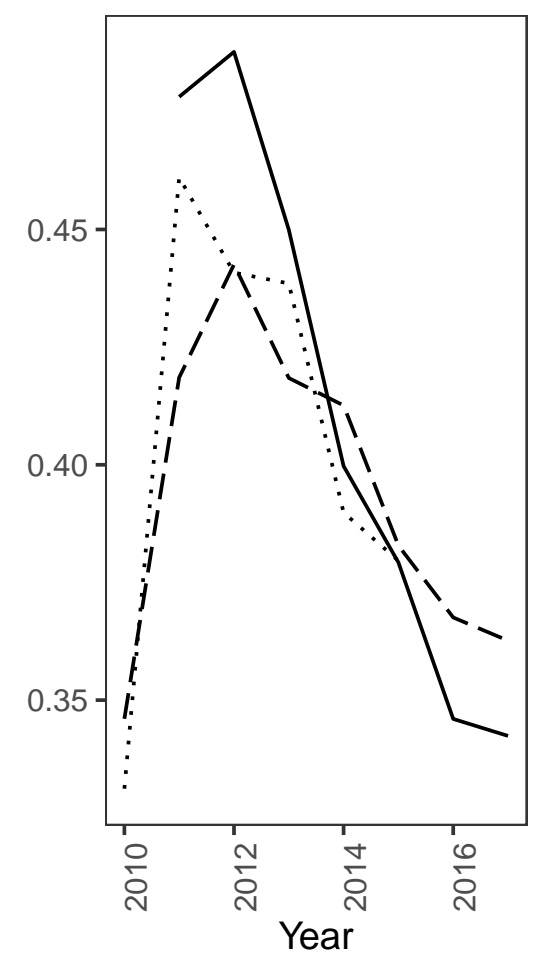

$--F \cdots O-E-O+E$ (c) BET

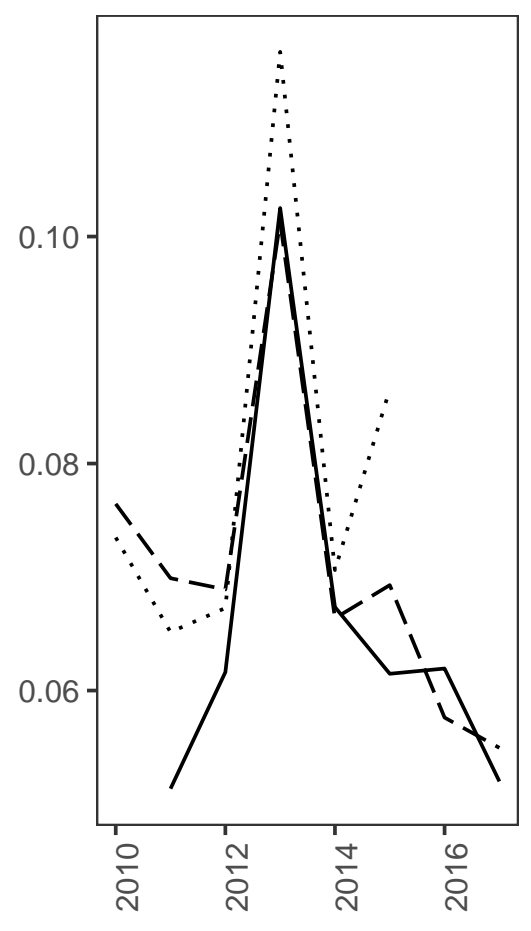

Figure 5: Average proportion of catch in each of the three major species of tunas as a function of set category and year. The tuna species are (a) SKJ=skipjack, (b) YFT=yellowfin and (c) BET=bigeye. The set categories are: $F=$ foreign FOB; $O-E=$ owned buoy without echosounder; $O+E=$ owned buoy with echosounder. 

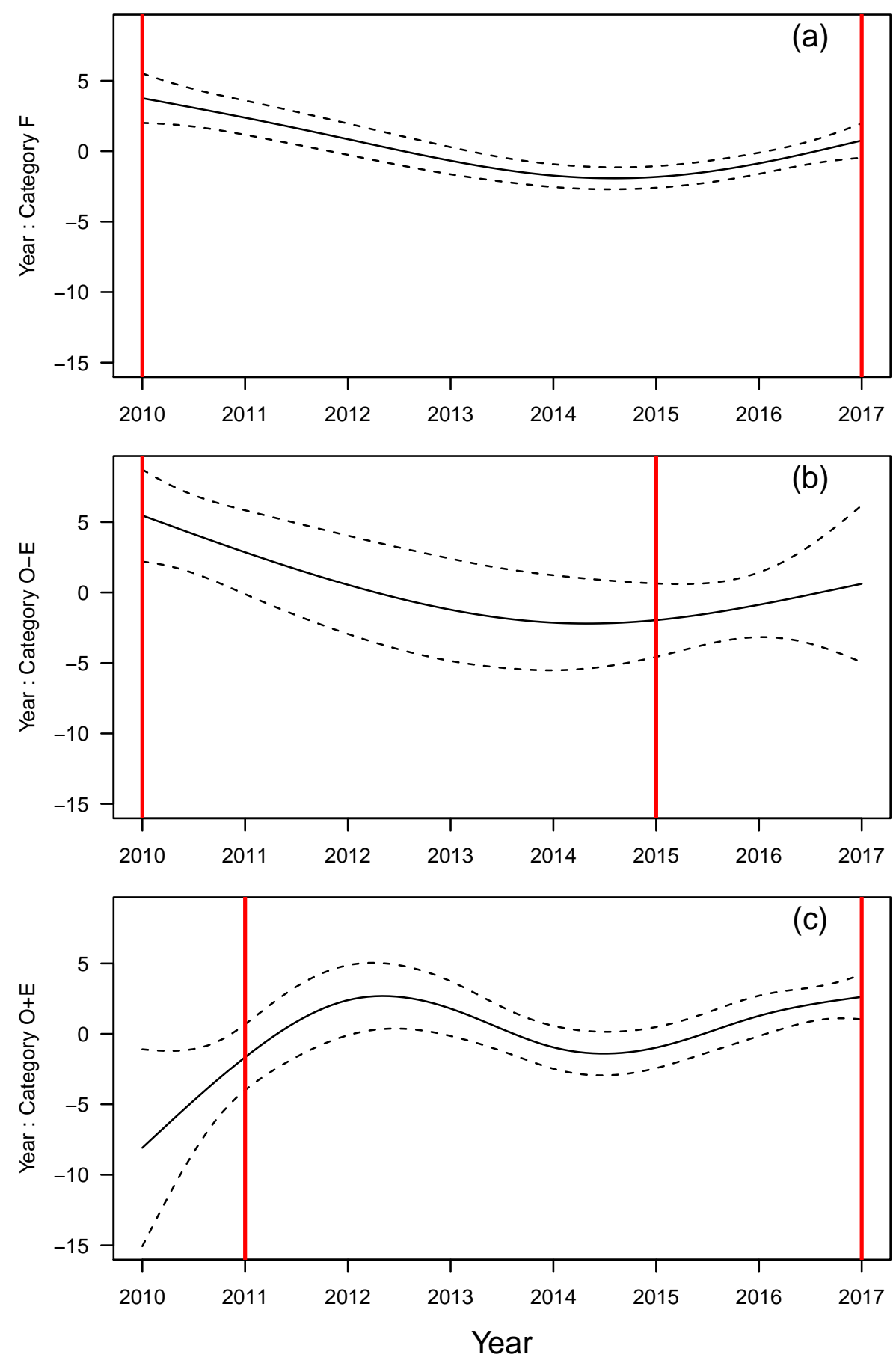

Figure 6: Effect of the interaction between year and set category estimated from GAM model A1 (see Table 1). The panels are from top to bottom: (a) $F$ =foreign FOB; (b) $O-E=$ owned buoy without echosounder; (c) $O+E=$ owned buoy with echosounder. Vertical red lines indicate the range of years for which we have data for the set category corresponding to a given panel. 

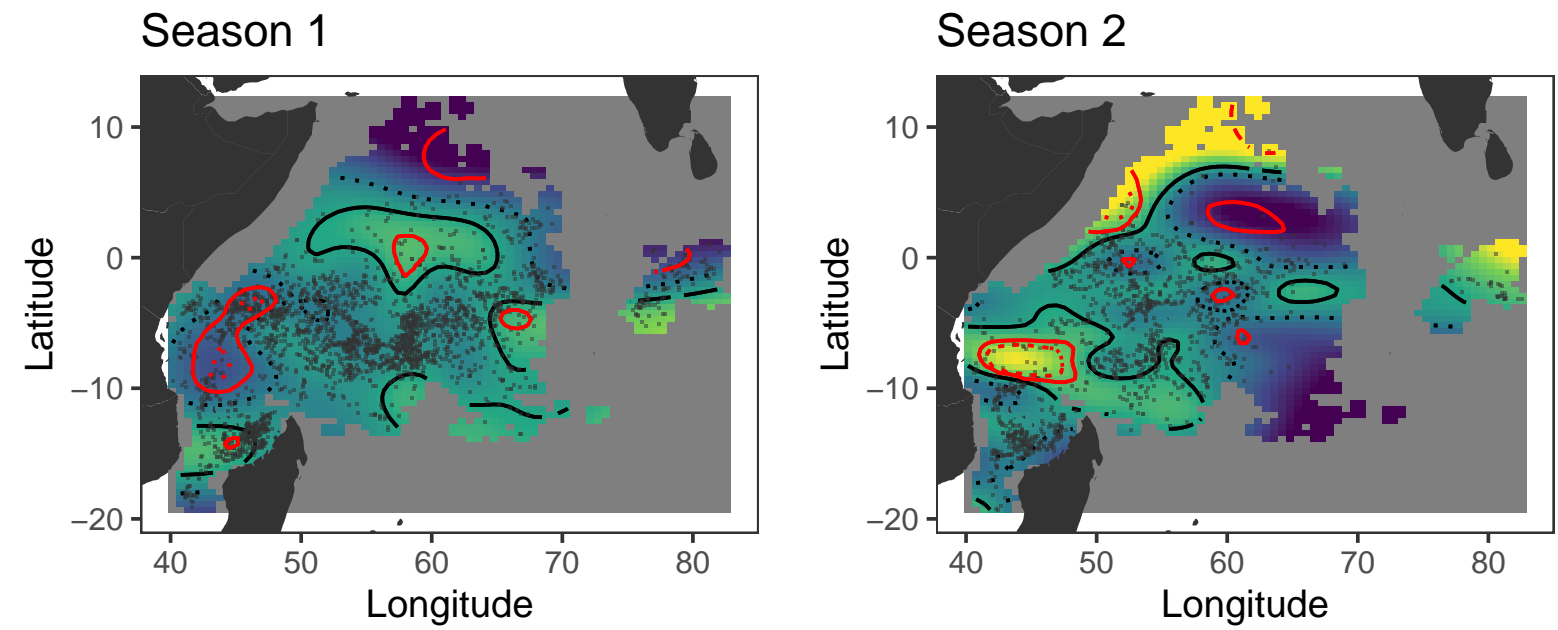

$\operatorname{Diff}(\mathrm{t})$
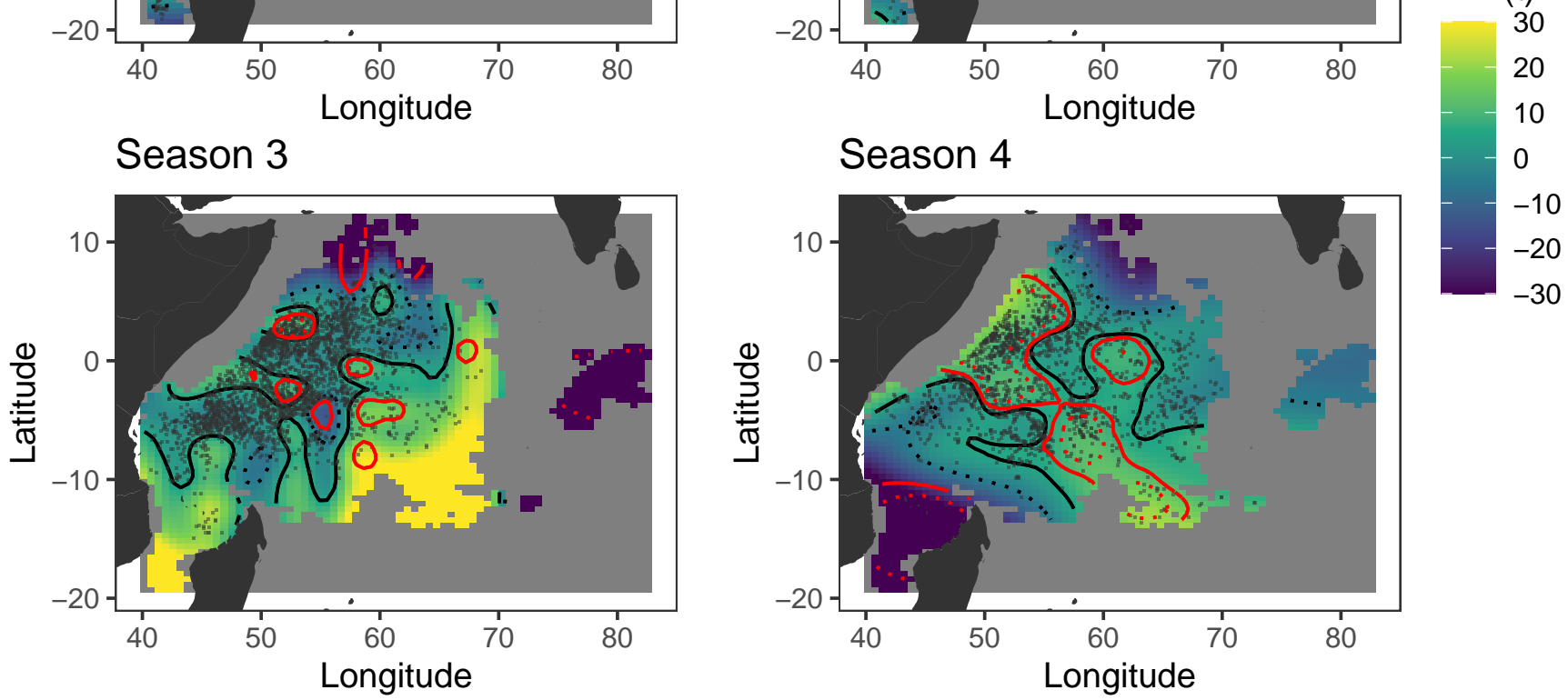

Figure 7: Difference between the smoothed spatial effects for fishing set categories $F$ and $O+E$ for each season from GAM model A3 (see Table 1). Colors indicate the difference between the two effects in tonnes, with positive values indicating higher catch per set for $O+E$ sets. Differences have been constrained to the range -30 to 30 tonnes so as to avoid anomalously large predictions in areas with little data (i.e., dark blue and bright yellow regions in peripheral areas for some reasons). Black solid and dotted contour lines indicate differences of +5 and -5 tonnes, respectively. Red solid and dotted contour lines indicate significant differences at the 0.05 and 0.01 level, respectively, as determined by the plotDiff function of the mgcViz package. 


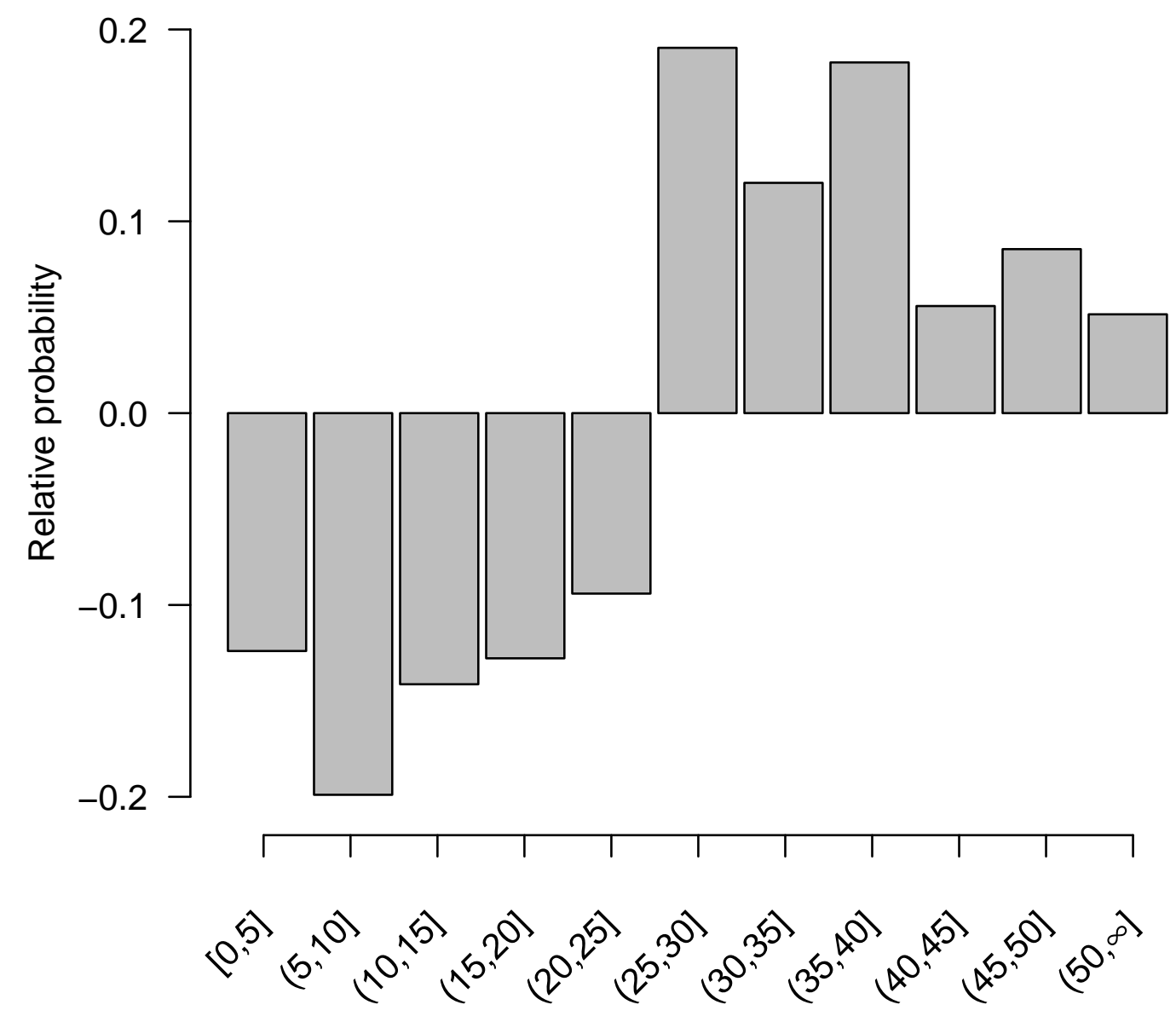

Catch size bin ( $\mathrm{t})$

Figure 8: Relative probability of sets being of type $F$ versus $O+E$ as a function of set catch size category for data from 2012-2017. Results show the coefficients of the terms corresponding to the different catch size categories in model N1 (see Table 1). Positive values along the y-axis indicate that a set of a given size is more likely to be of category $O+E$ than category $F$. As we are only concerned with relative probabilities, coefficients have been centered by removing the mean of all the coefficients. Note that the final size category is a plus class containing all sets greater than 50 tonnes. 